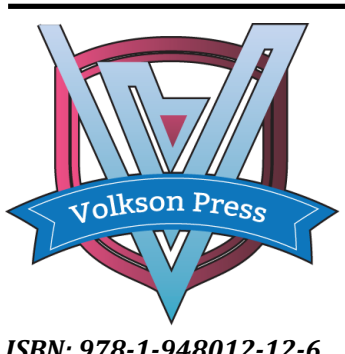

Contents List available at VOLKSON PRESS

New Materials and Intelligent Manufacturing (NMIM) DOI : http://doi.org/10.26480/icnmim.01.2018.124.126

Journal Homepage: https://topicsonchemeng.org.my/

ISBN: 978-1-948012-12-6

\title{
STRUCTURE, SITE OCCUPATIONS AND DIELECTRIC PROPERTIES OF LA AND TM CO-DOPED BATIO ${ }_{3}$ CERAMICS
}

\author{
Yue Liang1,2, Dayong Lu1* \\ ${ }^{1}$ Key Laboratory for Special Functional Materials in Jilin Provincial Universities, Jilin Institute of Chemical Technology Chengde Street 45, \\ Jilin, China \\ ${ }^{2}$ College of Chemistry, Jilin University, Qianjin Street 2699, Changchun, China \\ *Corresponding Author Email: dylu@jlict.edu.cn
}

This is an open access article distributed under the Creative Commons Attribution License, which permits unrestricted use, distribution, and reproduction in any medium, provided the original work is properly cited

\section{ARTICLE DETAILS}

\section{Article History:}

Received 26 June 2018

Accepted 2 July 2018

Available online 1 August 2018

\section{ABSTRACT}

The nominal $\left(\mathrm{Ba}_{1-\mathrm{x}} \mathrm{La}_{x}\right)\left(\mathrm{Ti}_{1-x} \mathrm{Tm}_{x}\right) \mathrm{O}_{3}(x=0.01-0.15)(\mathrm{BLTTm})$ ceramics were prepared at $1400{ }^{\circ} \mathrm{C}$ using a mixedoxides method. The structure, solubility limit, site occupations, and dielectric properties were investigated using Xray diffraction (XRD), Raman spectroscopy (RS), electron paramagnetic resonance (EPR), and dielectric measurements. The solubility limit of $\mathrm{La} / \mathrm{Tm}$ in the $\mathrm{BaTiO}_{3}$ lattice was determined by XRD to be $x=0.08$. BLTTm has a tetragonal perovskite structure for $x \leq 0.03$ and a pseudo-cubic structure for $0.05 \leq x \leq 0.08$. The dielectric thermal behavior of BLTTm with $x=0.05$ satisfied X6T specification, with $\varepsilon_{\mathrm{RT}}^{\prime}=1756$ and a very low $\tan \delta(<0.02)$ below $100{ }^{\circ} \mathrm{C} . \mathrm{Tm}^{3+}$ ions in BLTTm exhibited an asymmetric amphoteric behavior. Both reduction in Mn impurities of $\mathrm{Mn}^{4+} / \mathrm{Mn}^{3+}$ to $\mathrm{Mn}^{2+}$ and creation of high-intensity Ti vacancies are responsible for the very low $\tan \delta$ in BLTTm with $x$ $=0.05$.

\section{KEYWORDS}

La and Tm co-doped $\mathrm{BaTiO}_{3}$ ceramics, site occupations, X-ray diffraction, dielectric properties, electron paramagnetic resonance.

\section{INTRODUCTION}

Since the discovery of high-permittivity La/Ce co-doped barium titanate ceramics with Y5V specification $\left(-82 \% \leq\left(\varepsilon^{\prime}-\varepsilon^{\prime}{ }_{\mathrm{RT}}\right) / \varepsilon^{\prime}{ }_{\mathrm{RT}} \leq+22 \%\right.$ in a temperature range -30 to $85^{\circ} \mathrm{C}$ ) in 2006 , double rare-earth-doped $\mathrm{BaTiO}_{3}$ ceramics were widely developed [1-9]. Some ceramics are applied in the luminescent field $[2,3]$. Most ceramics are applied in the dielectric field, such as $\mathrm{BaTiO}_{3}$ co-doped with $\mathrm{La} / \mathrm{RE}(\mathrm{RE}=\mathrm{Tb}$, Dy, Ho, and Lu; this kind of ceramics requires higher sintering temperatures $\left(T_{s} \geq 1400{ }^{\circ} \mathrm{C}\right)$ and both dopants can be sufficiently incorporated into the $\mathrm{BaTiO}_{3}$ lattice [5-8]. The high-permittivity specifications above Y5V are often achieved in this kind of ceramics. Another kind of ceramics is core-shell structured ceramics prepared at low sintering temperatures $\left(T_{s} \leq 1320^{\circ} \mathrm{C}\right)$, such as $\mathrm{La} / \mathrm{Tm}$ codoped $\mathrm{BaTiO}_{3}$ [9]. The $\mathrm{La} / \mathrm{Tm}$ dopants are not incorporated into the $\mathrm{BaTiO}_{3}$ lattice but locate on the surfaces of ferroelectric $\mathrm{BaTiO}_{3}$ particles to form shells. This kind of ceramics generally satisfies X7R specification $\left(\left(\varepsilon^{\prime}-\varepsilon^{\prime}{ }_{\mathrm{RT}}\right) / \varepsilon^{\prime}{ }_{\mathrm{RT}} \leq 15 \%\right.$ in a range -55 to $\left.125^{\circ} \mathrm{C}\right)$. However, La/Tm co-doped $\mathrm{BaTiO}_{3}$ ceramics with sufficient dopants incorporations has been never explored.

In this work, $\mathrm{La} / \mathrm{Tm}$ co-doped $\mathrm{BaTiO}_{3}$ ceramics were prepared at $T_{\mathrm{s}}=$ $1400{ }^{\circ} \mathrm{C}$ so as to form sufficient dopants incorporations. The structure, solubility limit, site occupations, and dielectric properties of BLTTm were investigated using XRD, RS, EPR, and dielectric measurements. The EPR technique was employed to explore vacancy defects and the site occupations of La and Tm in BLTTm.

\section{EXPERIMENTAL}

The initial materials were reagent-grade $\mathrm{BaCO}_{3}, \mathrm{TiO}_{2}, \mathrm{La}_{2} \mathrm{O}_{3}$, and $\mathrm{Tm}_{2} \mathrm{O}_{3}$. Ceramics were prepared according to the nominal formula $\left(\mathrm{Ba}_{1-x} \mathrm{La}_{x}\right)\left(\mathrm{Ti}_{1-}\right.$ $\left.{ }_{x} \mathrm{Tm}_{x}\right)_{3}(x=0.01,0.03,0.05,0.08,0.09,0.15)$ (abbreviated BLTTm) using a conventional mixed oxide method with the same conditions as described elsewhere [1]. The final sintering condition was chosen as $T_{\mathrm{s}}=1400^{\circ} \mathrm{C}$ for $12 \mathrm{~h}$ in air.

Powder XRD measurements were performed between $20^{\circ} \leq 2 \theta \leq 85^{\circ}$ and in steps of $0.02^{\circ}$ using a DX-2700 X-ray diffractometer (Dandong Haoyuan) at room temperature (RT). All XRD data were collected at a collecting rate of $3 \mathrm{~s}$ per step. Unit-cell volume was calculated by software package (Accelrys Inc.) using $\mathrm{Cu} \mathrm{K \alpha} \alpha_{1}$ radiation $(\lambda=1.540562 \AA$ ). Raman spectra of ceramics powders were used a LabRAM XploRA Raman spectrometer (Horiba Jobin Yvon) at room temperature, with a $532 \mathrm{~nm}$ laser. Temperature dependences of the dielectric permittivity and the dielectric loss were measured at $1 \mathrm{kHz}$ from -75 to $200{ }^{\circ} \mathrm{C}$ at a heating rate of $2{ }^{\circ} \mathrm{C} / \mathrm{min}$ using a Concept 41 Dielectric/Impedance spectrometer (Novocontrol) with an applied voltage of $1 \mathrm{~V}$. EPR spectra were measured at RT using an A300 electron-spin resonance spectrometer system (Bruker BioSpin GMBH) at an X-band frequency of $9.86 \mathrm{GHz}$. The gyromagnetic factor $(g)$ was calculated by the relationship $h v_{0}=g \beta H$, where $h$ is the Planck constant $\left(h=6.626 \times 10^{-34} \mathrm{~J} \cdot \mathrm{s}\right), \nu_{0}$ is the microwave frequency, $\beta$ is the Bohr magnetron $\left(\beta=9.262 \times 10^{-24} \mathrm{~J} / \mathrm{T}\right)$, and $H$ is the magnetic field strength.

\section{RESULTS AND DISCUSSION}

\subsection{Crystalline Structure}

The powder XRD patterns of BLTTm are shown in Figure 1. The main perovskite phase had been formed in all samples. BLTTm with $x \leq 0.03$ crystallized in the single phase and had a tetragonal perovskite structure whereas for $0.05 \leq x \leq 0.08$, BLTTm converted to a pseudo-cubic structure

When $x \geq 0.09$, a secondary phase of a small amount of $\mathrm{Tm}_{2} \mathrm{O}_{3}$ (JCPDS Cards No. 82-2416) remained in BLTTm, as shown in Figure 2. This result indicates that the solubility limit of $\mathrm{La} / \mathrm{Tm}$ in $\mathrm{BaTiO}_{3}$ was estimated to be $x=0.08$. 


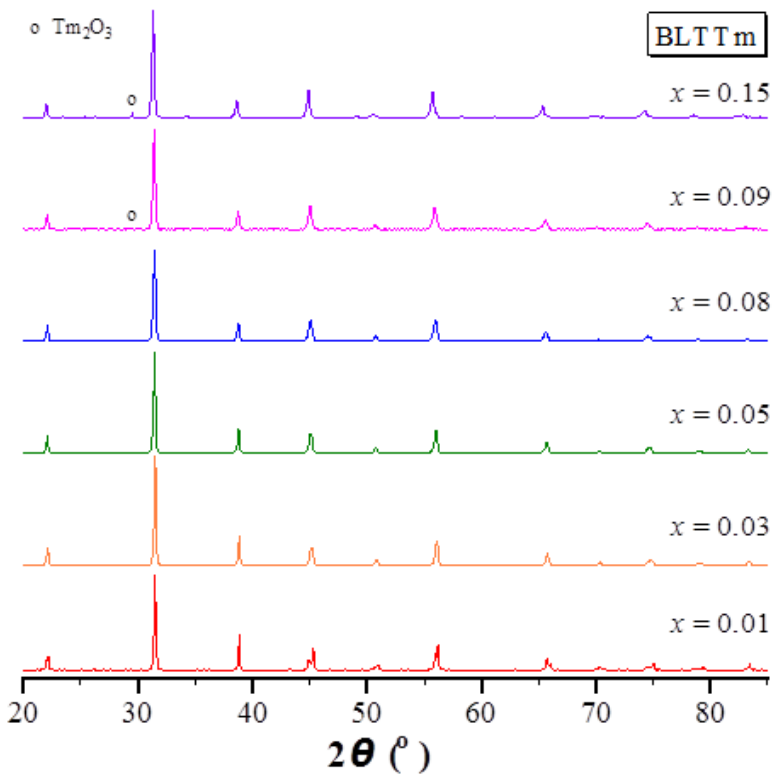

Figure 1: Powder XRD patterns of BLTTm ceramics with $\mathrm{x}=0.01-0.15$.

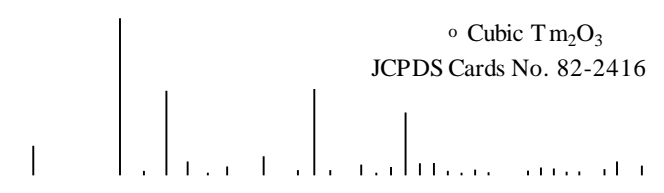

$\left(\mathrm{Ba}_{1-\mathrm{x}} \mathrm{La}_{\mathrm{x}}\right)\left(\mathrm{Ti}_{1-\mathrm{x}} \mathrm{Tm}_{\mathrm{x}}\right) \mathrm{O}_{3}(x=0.15)$

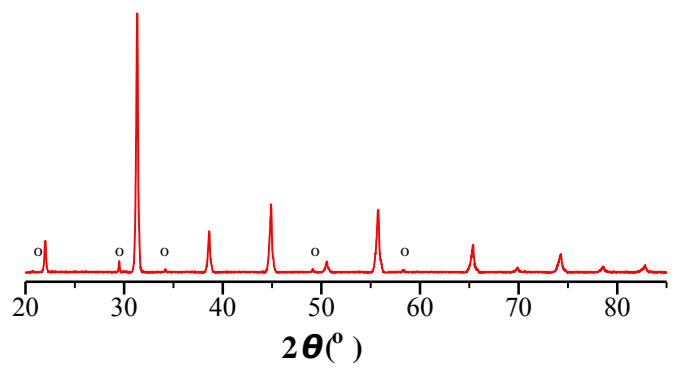

Figure 2: Powder XRD patterns of BLTTm with $\mathrm{x}=0.15$, and the simulated XRD pattern of the cubic Tm203.

The variations in lattice parameters $(a, c)$ and unit-cell volume $\left(V_{0}\right)$ as functions of $x$ are shown in Figure 3. It has been known that $\mathrm{La}^{3+}$ is exclusively substituted for Ba-site [5-8]. The $V_{0}$ of BLTTm is greater than that of the tetragonal $\mathrm{BaTiO}_{3}$ (JCPDS Cards No. 5-626) and increased with increasing $x$, revealing that $\mathrm{Tm}^{3+}$ ions were substituted dominantly for Tisites because 6-coordinate $\mathrm{Tm}^{3+}(0.88 \AA)$ is larger than $\mathrm{Ti}^{4+}(0.605 \AA)$ [10].

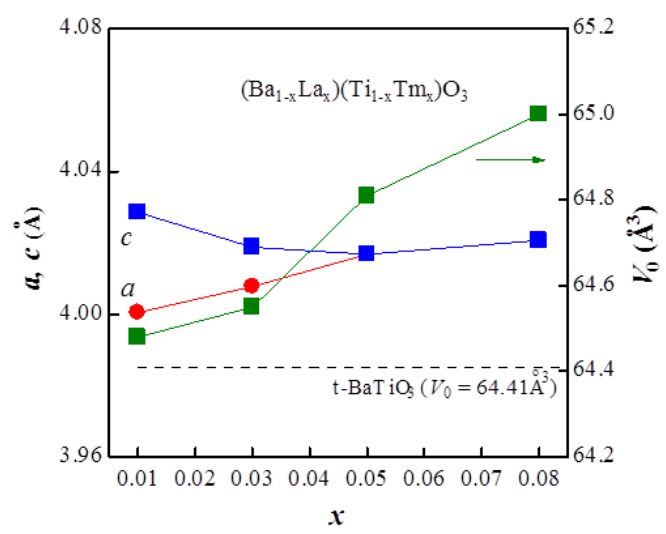

Figure 3: Variations in lattice parameters $(a, c)$ and $V 0$ as a function of $x$ for BLTTm

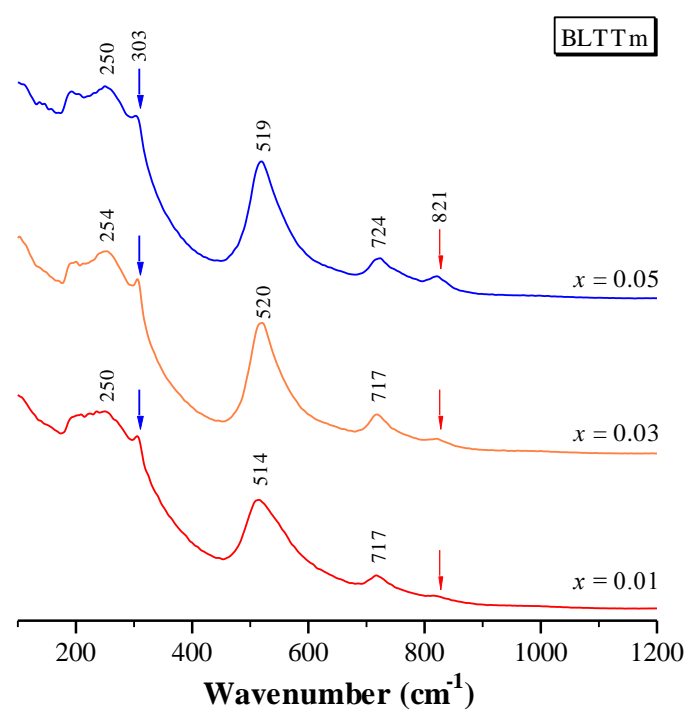

Figure 4: Raman spectra of BLTTm at RT.

The Raman spectra of the single-phase BLTTm at RT are shown in Figure 4. The tetragonal $\mathrm{BaTiO}_{3}$ exhibits four common optical modes: $\sim 260\left[\mathrm{~A}_{1}\right.$ $\left.\left(\mathrm{TO}_{2}\right)\right], \sim 305\left[\mathrm{~B}_{1}+\mathrm{E}(\mathrm{TO}+\mathrm{LO})\right], \sim 520\left[\mathrm{~A}_{1}\left(\mathrm{TO}_{3}\right)\right]$, and $\sim 720 \mathrm{~cm}^{-1}\left[\mathrm{~A}_{1}\left(\mathrm{LO}_{3}\right)+\right.$ $\left.\mathrm{E}\left(\mathrm{LO}_{3}\right)\right]$, respectively [11]. The sharp band at $303 \mathrm{~cm}^{-1}$ is an indication of the ferroelectric tetragonal phase. The presence of this sharp band for $x=$ 0.05 reveals that some ferroelectric phases such as tetragonal or orthorhombic existed in the pseudo-cubic BLTTm with $x=0.05$. An additional band appeared at $821 \mathrm{~cm}^{-1}$, which originates from the Raman charge effect [12]. The intensity of this band increased with increasing $x$, indicating an increase in the incorporation amount of both A-site and Bsite dopants, which is in accordance with the XRD result.

\subsection{Dielectric Properties}

The temperature dependences of the dielectric permittivity $\left(\varepsilon^{\prime}\right)$ and the dielectric loss $(\tan \delta)$ for BLTTm with $x=0.05$ are shown in Figure 5. The RT permittivity is $\varepsilon^{\prime}{ }_{\mathrm{RT}}=1756$. This sample exhibited a more flattened diffuse phase transition (DPT) behavior with a dielectric-peak temperature of $T_{\mathrm{m}}=42{ }^{\circ} \mathrm{C}$ and a very low $\tan \delta(<0.02)$ below $100{ }^{\circ} \mathrm{C}$, satisfying X6T specification $\left(-33 \% \leq\left(\varepsilon^{\prime}-\varepsilon^{\prime}{ }_{\mathrm{RT}}\right) / \varepsilon^{\prime}{ }_{\mathrm{RT}} \leq+22 \%\right.$ in a temperature range -55 to $105^{\circ} \mathrm{C}$ ) [13].

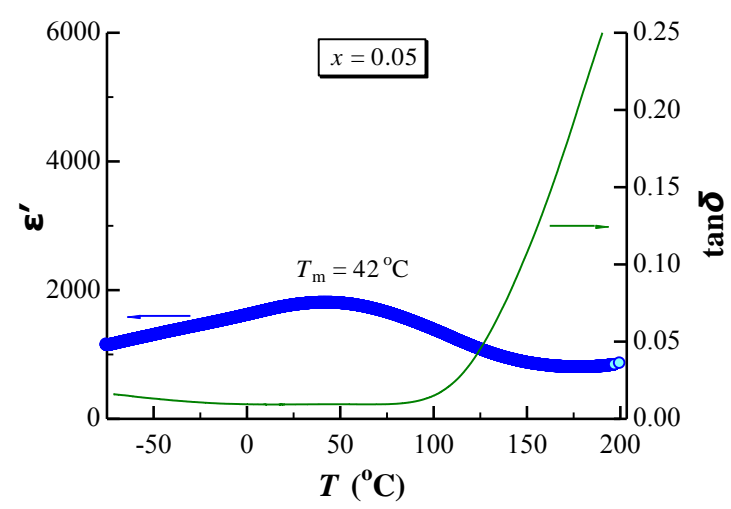

Figure 5: Temperature dependences of $\varepsilon^{\prime}$ and $\tan \delta$ for BLTTm with $\mathrm{x}=$ 0.05 , measured at $1 \mathrm{kHz}$. 


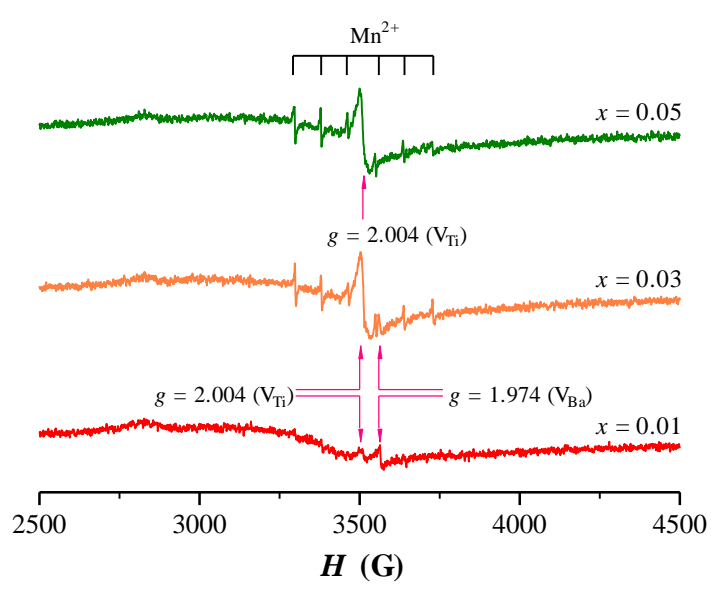

Figure 6: Room-temperature EPR spectra of BLTTm.

\subsection{EPR Investigations}

The room-temperature EPR spectra of BLTTm are shown in Figure 6. A $g$ $=2.004$ signal, which is associated with ionized Ti vacancies, appeared in all of the samples, and showed higher intensity for $x \geq 0.03[8,11]$. This reveals that some $\mathrm{Tm}^{3+}$ ions entered Ba-sites in $\left(\mathrm{Ba}_{1-x} \mathrm{La}_{x}\right)\left(\mathrm{Ti}_{1-x} \mathrm{Tm}_{x}\right) \mathrm{O}_{3}$, resulting in creation of Ti vacancies. A $g=1.974$ signal associated with ionized Ba vacancy defects was observed only in BLTTm with $x=0.01$ and 0.03 [14]. The line intensity of this signal decreased from $x=0.01$ to 0.03 , and it disappeared at $x=0.05$. This fact reveals that with Ba-sites were gradually filled with $\mathrm{Tm}^{3+}$ with increasing $x$. This further clarifies that $\mathrm{Tm}^{3+}$ in BLTTm exhibited an amphoteric behavior. A $\mathrm{Mn}^{2+}$ sextet signal was observed for $x \geq 0.03$. This signal originates from the reduction of $\mathrm{Mn}^{4+}$ or $\mathrm{Mn}^{3+}$ impurities in ceramics to $\mathrm{Mn}^{2+}$. Thus, both reduction in $\mathrm{Mn}$ impurities of $\mathrm{Mn}^{4+} / \mathrm{Mn}^{3+}$ to $\mathrm{Mn}^{2+}$ and creation of high-intensity Ti vacancies are responsible for the very low $\tan \delta$ in BLTTm with $x=0.05$.

\section{CONCLUSION}

The nominal $\left(\mathrm{Ba}_{1-x} \mathrm{La}_{x}\right)\left(\mathrm{Ti}_{1-x} \mathrm{Tm}_{x}\right) \mathrm{O}_{3}(\mathrm{BLTTm})$ ceramics were prepared at $1400{ }^{\circ} \mathrm{C}$ by a mixed-oxides method. The solubility limit of La/Tm in the $\mathrm{BaTiO}_{3}$ lattice was determined by XRD to be $x=0.08$. BLTTm has a tetragonal perovskite structure for $x \leq 0.03$ and a pseudo-cubic structure for $0.05 \leq x \leq 0.08$. A small amount of $\mathrm{Tm}_{2} \mathrm{O}_{3}$ remained as a secondary phase in BLTTm with $x \geq 0.09$. BLTTm with $x=0.05$ exhibits a more flattened diffuse phase transition behavior with $\varepsilon^{\prime}{ }_{\mathrm{RT}}=1756$ and a very low $\tan \delta(<0.02)$ below $100{ }^{\circ} \mathrm{C}$, satisfying X6T specification. $\mathrm{Tm}^{3+}$ ions in BLTTm are substituted dominantly for Ti-sites and slightly for Ba-sites, and therefore exhibit an asymmetric amphoteric behavior. Both reduction in $\mathrm{Mn}$ impurities of $\mathrm{Mn}^{4+} / \mathrm{Mn}^{3+}$ to $\mathrm{Mn}^{2+}$ and creation of high-intensity Ti vacancies are responsible for the very low $\tan \delta$ in BLTTm with $x=0.05$.

\section{ACKNOWLEDGMENTS}

This work was supported by the projects of the National Natural Science Foundations of China (21271084) and the Natural Science Foundations of Jilin Province (20160101290JC), and Changbai Mountain Scholar Distinguished Professor (2015047).

\section{REFERENCE}

[1] Lu, D.Y., Toda, M., Sugano, M. 2006. High-permittivity double rare earth-doped barium titanate ceramics with diffuse phase transition. Journal of the American Ceramic Society, 89 (10), 3112-3123.

[2] Ferreira, E.A., Cassanjes, F.C., Poirier, G. 2013. Crystallization behavior of a barium titanate tellurite glass doped with $\mathrm{Eu}^{3+}$ and $\mathrm{Er}^{3+}$. Optical Materials, 35 (6), 1141-1145.

[3] Dutta, D.P., Ballal, A., Nuwad, J., Tyagi, A.K. 2014. Optical properties of sonochemically synthesized rare earth ions doped $\mathrm{BaTiO}_{3}$ nanophosphors: probable candidate for white light emission. Journal of
Luminescence, 148 (7), 230-237.

[4] Jo, S.K., Park, J.S., Han, Y.H. 2010. Effects of multi-doping of rareearth oxides on the microstructure and dielectric properties of $\mathrm{BaTiO}_{3}$. Journal of Alloys and Compounds, 501 (2), 259-264.

[5] Lu, D.Y., Peng, Y.Y., Yu, X.Y., Sun, X.Y. 2016. Dielectric properties and defect chemistry of $\mathrm{La}$ and $\mathrm{Tb}$ co-doped $\mathrm{BaTiO}_{3}$ ceramics. Journal of Alloys and Compounds, 681, 128-138.

[6] Cui, S.Z., Lu, D.Y. 2015. Study on solubility of $\mathrm{La}^{3+}-\mathrm{Dy}^{3+}$ defects complexes and dielectric properies of $\left(\mathrm{Ba}_{1-\mathrm{x}} \mathrm{La}_{\mathrm{x}}\right)\left(\mathrm{Ti}_{1-\mathrm{x}} \mathrm{Dy}_{\mathrm{x}}\right) \mathrm{O}_{3}$ ceramics. Ceramics International, 41 (2), 2301-2308.

[7] Lu, D.Y., Guan, D.X., Li, H.B. 2018. Multiplicity of photoluminescence in Raman spectroscopy and defect chemistry of $\left(\mathrm{Ba}_{1-\mathrm{x}} \mathrm{R}_{\mathrm{x}}\right)\left(\mathrm{Ti}_{1-\mathrm{x}} \mathrm{Ho}_{\mathrm{x}}\right) \mathrm{O}_{3}(\mathrm{R}$ = La, Pr, Nd, Sm) dielectric ceramics. Ceramics International, 44 (2), 14831492.

[8] Lu, D.Y., Liu, T.T. 2017. Dielectric properties and defect chemistry of $\left(\mathrm{Ba}_{1-\mathrm{x}} \mathrm{Lax}_{\mathrm{x}}\right)\left(\mathrm{Ti}_{1-\mathrm{x}} \mathrm{Lu}_{\mathrm{x}}\right) \mathrm{O}_{3}$ ceramics. Journal of Alloys Compounds, 698, 967976.

[9] Kim, D., Kim, J., Noh, T., Ryu, J., Kim, Y.-N., Lee, H. 2012. Dielectric properties and temperature stability of $\mathrm{BaTiO}_{3}$ co-doped $\mathrm{La}_{2} \mathrm{O}_{3}$ and $\mathrm{Tm}_{2} \mathrm{O}_{3}$. Current Applied Physics, 12 (3), 952-956.

[10] Shannon, R.D. 1976. Revised effective ionic radii and systematic studies of interatomic distances in halides and chalcogenides. Acta Crystallography Section A, 32, 751-767.

[11] Lu, D.Y., Sun, X., Toda, M. 2007. A novel high-k 'Y5V' barium titanate ceramics co-doped with lanthanum and cerium. Journal of Physics and Chemistry of Solids, 68 (4), 650-664.

[12] Lu, D.Y., Han, D.D., Sun, X.Y. 2013. Structural evolution and dielectric properties of $\left(\mathrm{Ba}_{1-\mathrm{x}} \mathrm{Nd}_{\mathrm{x}}\right)\left(\mathrm{Ti}_{1-\mathrm{y}} \mathrm{Fe}_{\mathrm{y}}\right) \mathrm{O}_{3}$ ceramics. Journal of Alloys and Compounds, 576 (21), 24-29.

[13] Hennings, D., Schnell, A., Simon, G. 1982. Diffuse ferroelectric phase transitions in $\mathrm{Ba}\left(\mathrm{Ti}_{1-\mathrm{y}} \mathrm{Zr}_{\mathrm{y}}\right) \mathrm{O}_{3}$ ceramics. Journal of the American Ceramic Society, 65 (11), 539-544.

[14] Lu, D.Y., Cui, S.Z. 2014. Defects characterization of Dy-doped $\mathrm{BaTiO}_{3}$ ceramics via electron paramagnetic resonance. Journal of the European Ceramic Society, 34 (10), 2217-2227.

\section{ABOUT THE AUTHORS}

Professor Dayong Lu was born on July 31, 1967, in Liaoning, China. He earned a bachelor's degree in 1989 and a master's degree in 1996 from Jilin University and a PhD from Yamagata University in 2005. He taught at Jilin Institute of Chemical Technology (JLICT) in China. His research areas are high-permittivity ceramic materials, pharmaceutical analysis and quality control of traditional Chinese medicines, temperature-dependent measuring technology, and inorganic-organic composite materials. He is President of College of Materials Sciences and Engineering, Academic Leader of Materials Science and Engineering discipline, JLICT, Director of Key Laboratory of Special Functional Materials in Jilin Provincial Colleges and Universities. He was awarded New Century Excellent Talents in University, State Education Ministry (2007); Changbai Mountain Scholar Distinguished Professor (2016); and State Department Special Allowance (2015).

Yue Liang was born on February 12, 1994, in Gongzhuling, China. She earned a bachelor's degree from Tonghua Normal University of China in 2016. She is a postgraduate in Jilin University and is jointly-trained in Jilin Institute of Chemical Technology. Her research area is high-permittivity ceramic materials. 